\title{
O RECONHECIMENTO DA PERSONALIDADE PSÍQUICA DA CRIANÇA TRANSEXUAL COMO FORMA DE GARANTIR A DIGNIDADE HUMANA PREVISTA NA CONSTITUIÇÃO FEDERAL BRASILEIRA/1988 - UMA ANÁLISE À LUZ DO DIREITO E DA PSICANÁLISE.
}
RECOGNITION OF PSYCHIC PERSONALITY OF TRANSEXUAL CHILD AS FORM OF GUARANTEE THE HUMAN DIGNITY INTENDED IN BRAZILIAN FEDERAL CONSTITUTION/1988 - AN ANALYSIS PURSUANT THE LAW AND THE PSYCHOANALYSIS.

\author{
${ }^{1}$ Allyne Marie Molina \\ Moreira \\ 2Jeanne Marguerite Molina \\ Moreira
}

\section{RESUMO}

Tendo em vista que a Ciência Jurídica trabalha diretamente com o ser humano e suas subjetividades, o auxílio da Psicologia é primordial. Desta forma, apreendendo o conceito de transexualidade sob a perspectiva da psique, o presente trabalho debruçar-se-á sobre os estudos da dignidade humana, do direito de personalidade e de sua aplicabilidade nos casos de transtorno de identidade de gênero. A pesquisa é realizada em uma perspectiva transdisciplinar com o fim de chegar a respostas mais sólidas sobre o tema, não limitando-se às arestas cientificas de cada disciplinas, mas unido essas esferas rumo ao conhecimento e ao crescimento social.

Palavras-chave: Direito, Psicanálise, Criança transexual, Direito de personalidade, Personalidade psíquica, Dignidade humana

\begin{abstract}
Given that the Juridical Science works closely with humans and their subjectivities, the aid of psychology is paramount. Thus, learning the concept of transsexuality from the perspective of the psyche, this paper will focus on the study of human dignity, the personality of law and its applicability in cases of gender identity disorder. The survey is conducted in a transdisciplinary perspective in order to reach more solid answers on the subject, not limited to the edges of each scientific disciplines but united these spheres to knowledge and social growth.
\end{abstract}

Keywords: Law, Psychoanalysis, Transsexual chil, Personality of law, Psychic personality, Human dignity

\footnotetext{
${ }^{1}$ Especializacão em Responsabilidade Civil pela Universidade de Fortaleza -UNIFOR. Fortaleza. Ceará. Professora pela Universidade Federal do Ceará -UFC, Fortaleza, Ceará, (Brasil) Email: tutortreinamento@ gmail.com

${ }^{2}$ Mestre em Controladoria e Contabilidade pela Universidade de São Paulo -USP, São Paulo, Brasil. Professora pela Universidade Federal do Ceará -UFC, Fortaleza, Ceará, (Brasil).
} 


\section{INTRODUÇÃO}

A Ciência Jurídica nasce em uma fonte viva, dinâmica e transformadora: a sociedade. O Direito existe a partir do contexto social e não sobrevive distante deste. A análise forense deve ser realizada dentro de uma realidade cultural, de um tempo e de um território. Não há como se compreender um fato longe de sua história completa, assim como não há como considerar um processo afastado do mundo no qual este está inserido. (REALE, 2004) Tartuce (2014, p. 142) contribui com essa ideia afirmando que:

Conforme destacado por Pietro Perlingieri, o estudo do direito não pode deixar de lado a análise da sociedade na sua historicidade local e universal. Isso porque somente como tal análise se poderá individualizar o papel e o significado da juridicidade na unidade e na complexidade do fenômeno social (PERLINGIERI, Pietro. Perfil do Direito Civil..., 2002, p. 1). A ordem jurídica é um todo harmônico e os grandes princípio e garantias ditados pela Constituição Federal devem ter os contornos e características que a lei ordinária lhes der, sem infringi-los ou restringilos. (grifo original)

Através desta perspectiva de um direito social, que busca atender as reais demandas brotadas na sociedade, estudos transdisciplinares têm sido desenvolvido à fim de abraçar e acolher questões que antes eram encobertas. Paradigmas têm se quebrado e pensamentos, desfeitos. Valores que antes eram basilares são transformados a partir do momento que novos conceitos são aceitos. A sociedade está em mudança e a Ciência Jurídica não pode ficar aquém deste progresso. Com isso, pode-se dizer que a palavra Direito, esse arcabouço de leis e regras, está aproximando-se da palavras Justiça, onde a ética se sobrepõe a qualquer fôrma pré-concebida. Neste sentido, Santos et al (2006, on-line) aponta que:

Direito e Justiça são duas palavras semanticamente diferentes, porém o teor deveria ser o mesmo, pois estas palavras que inspiram estudos, trabalhos e artigos podem decidir o destino de toda uma nação. Parafraseando os ensinamentos de Kant, "duas cois as me enchem a alma de admiração e estupor, o Céu estrelado sobre mim, e a Lei Moral dentro de mim”. Falar em Direito é lembrar-se da Justiça e pensar nesta é discutir sobre o Social. A Ética é a Filosofia das ações humanas, como pronunciava Aristóteles. O Direito deve ser atrelado a Ética, assim como o corpo d'alma. A Justiça, o Direito e a Ética devem formar a engrenagem principal do aparelho que promove o bem estar social, impedir as explorações e opressões das classes mais fortes em detrimento às mais fracas.

Estas mudanças são observadas em diversos campos. Isso se dá porque, atualmente, o Direito tem como núcleo de sua análise o ser humano em sua integralidade. A preocupação moderna repousa em olhar os sujeitos a partir de suas demandas, de seus desejos, de seus sonhos, de seu psiquismo e de todos os elementos formadores da subjetividade. Com a promulgação da Constituição Federal de 1988, valores foram ponderados e novos arranjos sociais, admitidos. As relações privadas passaram a ser também interesse do Estado e 
garantias fundamentais como, por exemplo, a dignidade humana, foram resguardadas com mais furor. De acordo com Lemos (2015, on-line):

A Constituição da República de 1988 foi marco indelével para grandes mudanças no
sistema jurídico brasileiro como um todo, consagrando novos valores jurídicos,
passando a imprimir maior respeito e prestígio à dignidade da pessoa humana (CR,
art. $1^{\circ}$, III), como princípio fundamental. Neste prumo, o legislador passou a tutelar
direitos e garantias individuais e sociais, com o claro escopo de conferir às pessoas
condições mínimas para uma vida digna.

Pautando-se neste "novo" Direito garantido pela Constituição, optou-se por explorar o olhar jurídico no que tange ao sofrimento psicológico decorrente do transtorno de identidade de gênero na infância e suas possíveis soluções jurídicas na perspectiva atual. Para isso, pretende-se compreender a problemática da transexualidade, especialmente a manifestada ainda na infância, buscando mecanismos jurídicos pautados no Direito Civil-Constitucional, no que tange a dignidade da pessoa humana, e no Direito Civil de personalidade. Buscar-se-á desenvolver uma pesquisa a partir da visão desta minoria, que, em regra, são menosprezadas, tratadas como anormais e colocadas a margem de seu meio. (ARAUJO, 2000)

Notícias revelam que os sofrimentos psíquicos estão cada vez mais presentes nas salas de audiências da justiça brasileira e que, muitas vezes, as leis postas nos códigos não são suficientes para solucionar questões tão complexas. No entanto, falar sobre sentimentos e buscar dar à eles uma racionalidade sentenciável, não é algo fácil. Para isso, é preciso que haja um esforço transdisciplinar e que estudos doutrinários sejam desenvolvidos a fim de trazer soluções possíveis aos casos concretos. (COHEN, 2011)

As questões oriundas dos transtornos de sexualidade, em regra, trazem consigo problemáticas profundas e entrelaçadas a uma série de fatores que vão muito além do físico e daquilo que se pode ver e classificar como objetivo. Não há como tocar nesses temas sem que haja um olhar sensível sobre o sujeito em tese e sem que se analise o assunto a partir do ponto de vista da subjetividade. Leis petrificadas postas no ordenamento jurídico brasileiro não são capazes de, sozinhas, resolver tamanha demanda. O exposto na exordial de um processo no qual se tem, como tema principal, o sofrimento psicológico decorrente do transtorno de identidade de gênero na infância e a consequente angústia de pais que não sabem como ajudar a prole, pode configurar um exemplo em que os códigos não conseguem alcançar.

A sociedade tem clamado por uma justiça mais humanizada, onde se possa encontrar respostas para pleitos não cartesianos. Não há como falar em sujeitos sem se observar sua natureza singular. Neste trabalho, pretende-se estudar as crianças transexuais e os remédios jurídicos capazes de minimizar seus os sofrimentos. Assim, justifica-se a escolha do tema a 
partir do desejo da autora em pesquisar um assunto atual, com demandas ainda a serem trabalhadas e que entrelaçasse Direito e Psicologia em uma perspectiva transdisciplinar. Com a notícia divulgada no dia doze de fevereiro do corrente ano acerca da decisão proferida pela justiça do Mato Grosso, na qual o juiz autorizou a mudança do registro de nascimento de uma criança de nove anos que nasceu menino, mas se comporta e se vê como menina; optou-se por trabalhar o presente tema. $(\mathrm{G} 1,2016)$

Pautando-se nessa realidade social que aflora e clama por soluções mais apropriadas, o tema que ora se pretende construir pode ser considerado atual e ainda pouco explorado, reivindicando por si um estudo mais aprofundado. Para isso, almeja-se solucionar o seguinte problema: A partir da compreensão dos aspectos psíquicos que envolvem a transexualidade infantil, qual o entendimento jurídicos acerca do assunto, tomando-se como base os Direito Humanos, no que tange a dignidade da pessoa humana, e o Direito da Personalidade?

Diante da justificativa e da problemática acima apresentadas, fundou-se o objetivo geral do presente artigo no intuito de averiguar qual o entendimento jurídico diante de casos de transtorno de identidade de gênero manifestado ainda na infância, baseando-se nos Direito Humanos, no que tange a dignidade da pessoa humana, e no Direito da personalidade. No que diz respeito os objetivos específicos buscar-se-á compreender o transtorno de identidade de gênero à luz da psicanálise; meditar acerca do princípio constitucional da dignidade da pessoa humana e sua aplicação aos casos de transtorno de identidade de gênero; e, por último, avaliar o embate social entre identidade de sexo e identidade psíquica a partir dos conceitos fundamentais do Direito da Personalidade.

Para desenvolver o trabalho, utilizar-se-á mecanismos próprios da metodologia, arquitetando a presente obra da forma mais concreta possível. Os estudos serão realizados a partir de um modelo descritivo-analítico, através do qual se fará uma leitura interpretativa do material analisado, buscando compreender a partir dos dados científicos. (BEUREN, 2004). De tal modo, empregar-se-á como forma de pesquisa o método bibliográfico, buscando expor o problema a partir de referências teóricas. (CERVO; BERVIAN, 1953)

De acordo com Gil (1999), a pesquisa compreende o conjunto de procedimentos necessários na obtenção de dados sobre diferentes perspectivas. Com relação a abordagem do problema, optou-se pelo método qualitativo, adentrando no assunto de forma mais arraigada. (RICHARDSON, 1999) Quanto ao desenvolvimento dos objetivos, a pesquisa classifica-se como descritiva, pois visa esclarecer, explicar, e classificar o problema em comento; e 
exploratória, uma vez que se buscam maiores informações acerca da matéria em foco, apesar de não se ter a pretensão de esgotar o tema, mas apenas fomentar e contribuir para as discussões acadêmicas. (RAUPP; BEUREN, 2004)

Assim, pretende-se desenvolver uma pesquisa por meio de análise da literatura que aborde sobre o tema delineado, seja direta ou indiretamente, proporcionando a discussão acadêmica e uma considerável melhoria nas relações humanas. Debater sobre o comportamento dos sujeitos em suas mais diversas relações é sempre algo dinâmico e transformador. Para que se possa acompanhar esta dialética social, o Direito precisa se expandir, tentando alcançar as mutações que dão à sociedade um "novo" olhar a cada época.

Desse modo, acredita-se que a pesquisa a ser desenvolvida neste artigo irá trazer benefícios sociais consideráveis. Compreender a minoria e suas demandas e também compreender a sociedade como um todo. Falar em Direito a partir dos olhos da maioria é abandonar a parcela que, na verdade, mais precisa do acolhimento jurídico e que, em profundidade, dá a essa ciência a sua verdadeira razão de existir. Portanto, a pesquisa no campo do Direito da minoria possibilita à prática forense um trabalho humanizado, capaz de penetrar em lugares que as secas leis não são capazes de alagar.

\section{O TRANSTORNO DE IDENTIDADE DE GÊNERO}

A transexualidade pode ser considerada como um transtorno de identidade no qual o sujeito se sente diverso daquilo que está exposto em seu corpo. A anatomia não é compatível com a percepção pessoal de gênero, fazendo com que estas pessoas se sintam em um corpo que não é delas. Esta desordem gera, em regra, sérios problemas psíquicos e sociais, os quais podem desestruturar o indivíduo quando não tratados desde o início. Ser transexual significa não identificar-se com seu físico, não se reconhecendo em sua própria imagem. Ao conceituar o transexual, Diniz (1998, p. 604) descreve que:

Transexual: Medicina legal e psicologia forense. 1. Aquele que não aceita o seu sexo, identificando-se psicologicamente com o sexo oposto (Hojda), sendo, portanto, um hermafrodita psíquico (H Benjamim). 2. Aquele que, apesar de aparentar ter um sexo, apresenta constituição cromossômica do sexo oposto e mediante cirurgia para outro sexo (Othon Sidou). Tal intervenção cirúrgica para mulheres consiste na retirada dos seios, fechando a vagina e confecção de pênis artificial, e para os homens, na emasculação e posterior implantação da vagina (Paulo Matos Peixoto). 3. Para a Associação Paulista de Medicina, é o indivíduo com identificação psicossexual oposta aos seus órgãos genitais externos, com desejo compulsivo a mudá-los. 4. Aquele que, tendo morfologia genital masculina, sente-se psicologicamente mulher, rejeitando seu papel de "gênero" masculino até buscar a 
alteração de sua anatomia para assumir aparências físicas femininas. Correspondentemente, há mulheres em situação análoga (Aldo Pereira).

A partir de estudos realizados no campo da psicanálise, pode-se compreender o quanto o corpo diz sobre o sujeito e o quanto ele enraíza a subjetividade. Para Freud, o corpo não é o biológico e sim o corpo subjetivo constituidor do "eu" e de aspectos essenciais na elaboração do psiquismo. Lacan também expõe aspectos relevantes acerca da problemática do eu e do corpo apontando para a importância do significante deste como fonte de desejo e de gozo. Segundo o psicanalista, o corpo pode ser pensado de três maneiras: do ponto de vista do imaginário, o corpo como imagem; do ponto de vista do simbólico, o corpo marcado pelo significante; e do ponto de vista do real, o corpo como sinônimo de gozo. (CUKIERT; PRISZKULNIK, 2002)

Para Lacan, o corpo não se resume ao visível, ao posto em carne e osso, ou, simplesmente, ao corpo biológico. De acordo com o psicanalista, corpo é construído a partir do seu significante, daquilo que the é interno, intrínseco e inerente. Este corpo abastecido de simbolismo e de subjetividade são as raízes do sujeito, sendo os reais responsáveis por arquitetar, de fato, a estrutura funcional de cada indivíduo. O corpo é capaz de falar por si, manifestando seus desejos, seus anseios, e tudo aquilo que faz dele um ser único e individual. Há várias maneiras de expor a vontade e os sentimentos que compõem o interior de cada um. $\mathrm{Na}$ verdade, o mais importante a ser observado e analisado pela Psicologia não é a fala em si e sim o arsenal de gestos, expressões e comportamentos manifestados pelos pacientes. $\mathrm{O}$ corpo se expressa em uma verdade incontestável, despindo o ser de todo e qualquer manto de mentira que the possa encobrir. Ao tratar sobre este assunto Nasio (1993, p.149)

(...) o corpo que interessa à Psicanalise não é um corpo de carne e osso, mas um corpo
tomado como um conjunto de elementos significantes. O corpo falante pode ser, por
exemplo, um rosto, na medida em que um rosto se compõe de linhas, expressões
(...). O adjetivo "falante" não indica que o corpo fale conosco, mas que ele é
significante, ou seja, que comporta significantes que falam entre si. (...) Quando
um rosto suscita um sentimento, ele é um corpo-imagem; mas, quando o mesmo rosto
desperta um dizer imprevisto, ele é um corpo-significante.

Entende-se que a transexualidade vai além da questão física, do desejo pelo mesmo sexo ou pela simples vontade de se transvestir. É uma desordem originada na subjetividade, no psiquismo, atingindo diretamente a autoimagem. $\mathrm{O}$ sujeito não se reconhece naquele corpo que the foi posto, tornando-se prisioneiro de seu próprio físico. Percebem-se como nascidos em um corpo errado, aspirando afastar-se de si para aproximar-se daquilo que desejariam ser. Expressar essa vontade é uma fonte de libertação, retirando-os desta caixa corpórea, desta realidade, que não é compatível com o tamanho de seus sonhos. Esse transtorno psicológico 
tem sido estudado em várias culturas e a partir de diversas ciências. Ao tratar do assunto Elvira (2012, p. 299) afirma que:

La Organización Mundial de la Salud califica a la transexualidad como un trastorno de identidad sexual, caracterizado por la incongruencia entre el sexo anatómico y la identidad sexual, entendiendo por tal la consciencia de pertenecera un sexo determinado, y viene definido como la disociación sexual centrada en la creencia fija de que los caracteres sexuales externos no son los que corresponden a la persona, de tal modo que la conducta resultante del sujeto se dirige, bien hacia el cambio de los órganos sexuales por medio de operación quirúrgica, bien hacia el ocultamento completo del sexo operante adaptando el vestido e los modales del sexo opuesto.

Acreditando ter nascido no corpo errado os transexuais não aceitam tal situação, podendo ser causa de transtornos psíquicos graves. Repugnam a sua forma física e passam a ter comportamentos próprios do sexo oposto. Essa conduta nem sempre é aceita na família e no meio social em que vivem, tornando a vida desses sujeitos um lugar de pleno desconforto. $\mathrm{O}$ serviço de saúde de diversas capitais brasileira prestam assistência a esse público, amparandoos nas mais diversas áreas. No entanto, antes de ser resolvido a incompatibilidade física gerada pela transexualidade, o sujeito passa por densas dificuldades nos seus relacionamentos, fazendo com que ele vá se fechando em seu interior. (ARAN; MURTA, 2009)

Revelar o inconsciente através de atos corporais pode ser próprio da natureza de uma possível punição advinda do grupo em que esta pessoa está inserida, sendo fonte de repúdio e marginalização. Percebe-se que a maioria das pessoas que chegam a esses atendimentos, já estão fragilizadas e machucadas de uma forma muito profunda. São dores que, em geral, se iniciam na infância e perduram por toda a caminhada até a possível solução. A diferença entre a identidade física e a identidade psíquica causa um intenso sofrimento social e psicológico, fazendo com que eles não se sintam prontos para transitar livremente na sociedade. Conforme Aran e Murta (2009, on-line):

Na realidade brasileira, usuários(as) transexuais que chegam aos serviços de saúde
encontram-se, muitas vezes, numa condição de extrema vulnerabilidade psíquica,
física e social, sendo a "saúde" não apenas o que vai proporcionar o tratamento
necessário e desejado, mas, muito provavelmente, o que permitirá a construção de
uma rede de reconhecimento e inclusão social para estas pessoas.

De acordo com a Constituição da Organização Mundial da Saúde - OMS (1946), a saúde não se limita ao biológico. Para a OMS, "a saúde é um estado de completo bem-estar físico, mental e social, e não consiste apenas na ausência de doença ou de enfermidade". Entende-se, portanto, que não há como se falar em saúde sem que se considere o sujeito como um todo, de forma única, individual e completa. Não se consente mais a observação 
meramente dualista dos indivíduos, como se mente e corpo fossem algo separado. Hoje se analisa a totalidade dos seres e não simplesmente a soma de suas partes. É a partir do todo que o indivíduo se faz e se refaz, construindo suas pulsões de vida e de morte, fontes que impulsionam a existência humana. Os aspectos psicológicos e sociais são extremamente importantes, configurando pilares do ser humano. Contribuindo com essa ideia, CANDIDO (2003, on-line) afirma que:

É a partir dessa premissa, que podemos falar sobre a modernidade de Freud ao conceber um corpo vivido que não se reduz ao corpo biológico, idéia precursora da noção de pulsão como algo que surge do somático e funciona como um estímulo para o psíquico. Articulando mente e corpo, Freud rompeu com a Biologia e com as definições tradicionais a respeito do assunto. Era materialista, pois não desprezou o funcionamento cerebral, como demonstra no Projeto, mas, com o psiquismo, soube se descolar do 'físico', e abrir portas para sua metapsicologia, inventando o conceito de pulsão. Temos aí o materialista e o mentalista. Assume que mente e cérebro são inseparáveis, e que, ao mesmo tempo, a entidade mental não se reduz ao cérebro. $\mathrm{E}$ novamente nos deparamos com um paradoxo: o monis mo e o dualismo.

Penso que um dos grandes méritos de Freud tenha sido justamente a capacidade de apontar a inadequação dos termos dualismo-monismo e materialismo-mentalismo quando se pretende descrever a natureza da interação mente-corpo. Concordamos com Sperry (1986): as categorias clássicas não descrevem adequadamente essa relação, pois "mentalismo não é sinônimo de dualismo assim como materialismo não é sinônimo de monismo" (p.79).

Se tivermos, obrigatoriamente que encaixar Freud nessas definições, poderíamos aproximar sua teoria de um monismo mentalista, pois compreendia que os padrões mentais são gerados a partir dos eventos neurais, mas apresentamqualidades próprias, cujos princípios são diferentes dos neurofisiológicos. Além disso, talvezFreud tivesse uma compreensão daquilo que enfatiza Searle (1995): o fato de uma característica ser mental não implica que não seja física; o fato de uma característica ser física não implica que não seja mental; a mente, enquanto subjetiva, enquanto qualitativa, é física, e é física porque mental. Tudo isso mostra a inadequação do vocabulário tradicional. E Freud é moderno porque conseguiu desafiá-lo, e, com isso, criar um conceito ímpar para a compreensão da constituição do psiquismo: a pulsão. (grifo original)

Apesar do Manual de Diagnóstico e Estatística dos Transtornos Mentais, 5. a edição DSM-5, publicado pela Associação Americana de Psiquiatria, ter alterado a nomenclatura que se refere à transexualidade para o termo "disforia de gênero" como uma forma de maquiar a discriminação, mas longe de retira-la totalmente do rol de doença; a última versão da Classificação Internacional de Doenças - CID 10, publicada pela Organização Mundial da Saúde - OMS; ainda considera explicitamente o transtorno de identidade de gênero como uma patologia. Isso fere profundamente aqueles que sentem e passam por esse processo. Ser considerado doente é algo estigmatizante, retirando do sujeito o sentimento de pertencimento e igualdade junto a seus pares. Como bem explana Dias (2014), 'considerar o outro como doente é muito mais fácil que ver nele um igual, com trajetórias diferentes mas, sobretudo, com a mesma cidadania dos demais integrantes da sociedade'. 
Conforme a citada autora, é preciso despatologizar a transexualidade, bem como lutar pelos direitos humanos, cidadania, democracia e reconhecimento identitário dos transexuais. O termo transexualismo já é pejorativo por sua própria nomenclatura, a qual carrega consigo um sufixo atrelado a ideia de doença (DINIZ, 2001) e este não é o entendimento do presente trabalho, o qual busca entender a transexualidade apenas como uma forma não comum de perceber o próprio corpo no que tange aos aspectos sexuais e de gênero, mas não como algo a ser tratado. Ao trazer essas questões através de um documentário, a diretora Camila Biau e sua protagonista Daniela Glamour Garcia (apud BENTO; PELUCIO, 2012), revelam que:

\begin{abstract}
'Você usa rosa ou você usa azul? Você tem pinto ou você tem buceta? Você usa shorts e fica brincando de Homem-Aranha ou você tem que ficar penteando o cabelo de uma Barbie? Cada ser humano tem as suas verdades, tem as coisas as quais tem que buscar e realizar. Alguns seres simplesmente têm uma incompatibilidade sexual com o corpo, Isso não é uma transformação, isso é um fato. Você nasceu mulher, mas você é um homem. Aí você se pega tendo que fazer da sua vida uma transformação inteira porque todo mundo quer que seja.' (Daniela Glamour Garcia, depoimento à Camila BIAU, 2011.)

Daniela Glamour Garcia olha para a câmera com olhos inquietos. Está visivelmente sensibilizada pelos meses em que esteve protagonizando um documentário sobre identidades sexuais a partir de uma perspectiva queer. Dani, como gosta de ser chamada, se sente incompreendida, mas nunca doente, patologizável, curável. Daniela gostaria de não ter de pensar o tempo todo em sua sexualidade, em seu corpo, em seus desejos. Participar do documentário Além das sete cores, dirigido por Camila Biau, tornou essas reflexões prementes, presentes e um tanto opressivas. Daniela, que inicia as filmagens coreografando passos pela Rua Augusta, no coração da capital paulista, mas chega ao final do filme visivelmente sensibilizada. Sua última fala registra sua busca por termos de identificação que possam tornar sua vida habitável, fora dos referentes patologizantes e psicologizantes hoje disponíveis. Naquela última cena, Dani parece estar cansada dessa luta; talvez por isso, ao fim de sua participação no documentário, tenha iniciado o processo transexualizador, oferecido pelo Hospital das Clínicas, em São Paulo. Foi buscar nos discursos médicos e psi (referentes à psicanálise, psicologia e psiquiatria) os termos de sua busca por inteligibilidade. (grifo original)
\end{abstract}

A dificuldade de aceitação pessoal e o consequente afastamento social, geram no transexual angustias que muitas vezes chegam aos tribunais através de um processo escrito com vergonha e tristeza. Nos autos estão palavras cheias de dor, de impotências e de incapacidades. Neste sentido, cabe ao Direito, enquanto Ciência Social, proporcionar uma escuta diferenciada e soluções sólidas ao caso concreto, sendo meio facilitador de transformação e alívio. Deve-se observar que antes de transexual, o judiciário está diante de um sujeito munido de sentimentos mal tratados. Aceitar como ele se considera psiquicamente é entende-lo em sua subjetividade, elemento este formador essencial do ser humano. 


\section{O PRINCÍPIO CONSTITUCIONAL DA DIGNIDADE DA PESSOA HUMANA E SUA APLICAÇÃO AOS CASOS DE TRANSTORNO DE IDENTIDADE DE GÊNERO}

Com o advento da Constituição da República Federativa do Brasil de 1988, ora vigente, princípios fundamentais foram esboçados em seu texto com o fim de minimizar as diferenças, lutar pela homogeneização social e aproximar governantes e governados através do modelo democrático estabelecido. A Carta Magna se constrói em bases sociais e inteiramente voltadas para o bem estar de seus indivíduos. A Constituição faz brotar direitos em prol da cidadania, da dignidade e do respeito. Neste sentido, logo no artigo $1^{\circ}$ o texto prescreve os fundamentos da República Federativa do Brasil, colocando a dignidade da pessoa humana como um deles. (OLIVEIRA; OLIVEIRA, 2011)

A partir deste entendimento, novos olhares foram lançados àqueles que se encontravam marginalizados. Os então classificados como Direitos Humanos adentraram o Ordenamento Jurídico brasileiro pela porta constitucional e trouxeram significativas mudanças. Nesse momento, valores antes deixados de lado passaram a ser considerados fundamentais e a sociedade tornou-se inclusiva e preocupada com o bem-estar de todos. Mudanças também foram estabelecidas na relação do Estado com os cidadãos, onde aquele deixou de limitar-se ao que pode ser considerado de interesse público e inseriu-se nas relações privadas, garantindo prerrogativas fundamentais prescritas na Carta Magna. Ao conceituar Direito Humanos, Silva e Bonifácio (2012, on-line) advertem que:

Os Direitos Humanos correspondem àqueles direitos fundamentais aos quais todo
homem deve ter acesso, em virtude puramente de sua qualidade de ser humano e
que, portanto, toda a sociedade, que se pretenda uma sociedade autenticamente
humana, deve assegurar aos seus membros. Segundo o ensinamento do professor
Ricardo Cunha Chimente: 'por direitos humanos hão de se entender as prerrogativas
inerentes à dignidade da espécie humana e que são reconhecidos na ordem
constitucional'

Assim, compreende-se que os direito fundamentais, em especial no que diz respeito à dignidade humana, devem ser preservados e que sem eles não há como se falar em constitucionalidade. Em um momento pós-ditadura, as relações e condutas que ferem os direitos cravados no seio constitucional não podem ser toleradas nem suas consequência suportadas. Estar em consonância com a Constituição é vivenciar a dignidade em sua plenitude e ver garantido as suas bonanças. Assim, ressaltaram Kumagai e Marta (2010, on-line):

A Carta de 1988 apresenta como característica a clareza no que se refere à importância da dignidade humana, em consequência de todo o contexto histórico já relatado. Nesse sentido, como pano de fundo, a Constituição Federal do Brasil de 1988 foi elaborada num cenário de pós-ditadura e de abertura política, aliados ao 
profundo sentimento da necessidade de solidariedade entre os povos. Assim, nota-se a expressão de uma nova era das garantias individuais, resultado de lutas e abusos no árduo caminho do reconhecimento dessas liberdades, até se alcançar a promulgação desse texto.

Através desse conceito de dignidade, entende-se que a dignidade humana é um dos maiores bens que se pode ter, é a base dos direitos fundamentais, junto ao bem da vida e da liberdade. Por esse motivo, o legislador teve o cuidado de colocar expressamente na Constituição Federal, em seu artigo $1^{\circ}$, inciso III, que "A República Federativa do Brasil, formada pela união indissolúvel dos Estados e Municípios e do Distrito Federal, constitui-se em Estado Democrático de Direito e tem como fundamentos: III - a dignidade da pessoa humana". Neste diapasão, Moraes (2003, p. 83-84) ressalta que:

\begin{abstract}
A Constituição consagrou o princípio e, considerando a sua eminência, proclamou-o entre os princípios fundamentais, atribuindo-lhe o valor supremo de alicerce da ordem jurídica democrática. Com efeito, da mesma forma que Kant estabelecera para a ordem moral é dignidade humana que a ordem jurídica (democrática) se apóia e se constitui.
\end{abstract}

Ao tratar acerca dos Direitos Humanos e de seus resultados ao meio social, Lôbo (2009), aponta para o previsto na Declaração Universal dos Direitos Humanos no que tange ao assunto, ressaltando a sua essencialidade junto a vida integral dos indivíduos. Traz a proposta de que o Princípio da Dignidade da Pessoa Humana está intimamente relacionado ao Princípio da Solidariedade, tendo em vista que o sujeito se constrói na existência consigo e, mais ainda, na coexistência com o grupo. Não há como se falar em ser humano longe de seus semelhantes. A humanidade é uma característica aprendida com a convivência e os princípios constitucionais vêm direcionar estas relações. De acordo com o autor:

[...] da Declaração Universal dos Direitos Humanos contida em seu art. $1^{\text {o. }}$ 'Todos os seres humanos nascem livres e iguais em dignidade e direitos'. No mundo atual, o foco na pessoa humana é matizado com a consciência da tutela jurídica devida aos outros seres vivos, (meio ambiente) e da coexistência necessária, pois a pessoa existe quando coexiste (solidariedade). (LÔBO, 2009, p. 39)

A respeito do assunto ora debatido, Tepedino (2002), ratifica a ideia de um Direito voltado para o bem-estar social e em confronto declarado com a desigualdade, o repudio e a marginalização social. Para o autor, é através da dignidade humana e de princípios afins que a sociedade cresce como celular organizada e saudável, afastando tudo aquilo que não é desta ordem. Acrescenta ainda que um estado de direito vai além do escrito no texto legal e que, mesmo quando não expresso, deve-se observar os princípios como fontes formadoras de um Estado organizado e livre de indiferenças. Conforme o jurista:

Com efeito, a escolha da dignidade da pessoa humana como fundamento da República, associada ao objetivo fundamental de erradicação da pobreza e da marginalização, bem como de redução das desigualdades sociais, juntamente coma 
previsão do $\S 2^{\circ}$ do artigo $5^{\circ}$, no sentido da não exclusão de quaisquer direitos e garantias, ainda que não expressos, mas decorrentes dos princípios adotados pelo Texto Maior, configuram uma verdadeira cláusula geral de tutela e promoção da pessoa humana, tomada como valor máximo pelo ordenamento. (TEPEDINO, 2002, p. 27-28)

Diante do exposto e trazendo estes conceitos para o tema ora desenvolvido, entendese que aceitar o fato de que transexuais não possam expressar quem realmente são, é furtar- lhes a possibilidade de viverem dignamente, ferindo completamente a proposta constitucional. A dignidade é algo que é inerente de cada sujeito, mas também é algo construído e defendido socialmente. Todos têm o direito de ser e estar na sociedade da forma que the for possível, admirável e conveniente, salvo se ferir o espaço de outro. Entende-se, portanto, que o transtorno de identidade de gênero não tem por genealogia esta invasão de limites, o que não explica o porquê de tamanho repudio. Não aceitar esta dificuldade de adequação entre corpo e psiquismo de um outro sujeito é ferir violentamente a liberdade deste de se perceber da forma que lhe for adequada, afastando totalmente o entendimento de dignidade humana. Nunes (2002, p. 4950 apud DONIZETTI, 2007, p.57) colabora com o entendimento do conceito de dignidade ao colocar que:

[...] a dignidade nasce com a pess oa. É-lhe inata. Inerente à sua es sência. Mas acontece que nenhum indivíduo é isolado. Ele nasce, cresce e vive no meio social. E aí nesse contexto sua dignidade ganha - ou, como veremos, tem o direito de ganhar - um acréscimo de dignidade. Ele nasce com integridade física e psíquica, mas chega um momento de seu desenvolvimento que seu pensamento tem de ser respeitado, suas ações e seu comportamento - isto é, sua liberdade - sua imagem, sua intimidade, sua consciência - religiosa, cientifica, espiritual - etc., tudo compõe sua dignidade [...] Ter-se-á, então, que incorporar no conceito de dignidade uma qualidade social como limite à possibilidade de garantia. Ou seja, só é garantia ilimitada se não ferir outra.

O Direito comparado também tem se debruçado veementemente no tocante aos aspectos próprios da teoria da dignidade humana. Tribunais já compreendem a importância da análise de casos a partir deste olhar, afastando das sentença qualquer tipo de discriminação e desrespeito. Desta forma, a Ciência Jurídica tem trabalhado para garantir à todos uma vida digna, onde haja a garantia do bem-estar e da integridade física e psíquica de todos. Neste sentido, McCrudden (2008) descreve que:

Dignity also has played a key role increasingly important in the judicial interpretation of the meaning of constitutional prohibitions against discrimination in Canada. Indeed, the purpose of the right to equality in the Canadian Charter, according to the Supreme Court of Canada, is: 'prevent the violation of essential human dignity and freedom through the disadvantage of imposing, stereotyping or political or social prejudice, and promote society in which all persons enjoy equal recognition before the law as human beings or as members of Canadian society, equally capable and deserving of concern, respect and consideration '. In Law in Canada (Minister of Employment and Immigration), Iacobucci J, writing for a unanimous court, described the importance of human dignity, "human dignity means that an individual or group feels self-esteem and self-esteem. it is concerned with the 
physical and psychological integrity and empowerment. human dignity is harmed by unfair premise treatment personal traits or circumstances which do not relate to individual needs, capacities or merits. human dignity is harmed when individuals and groups are marginalized, ignored or devalued, and is enhanced when laws recognize the full place of all individuals and groups within society.

Desta forma, a dignidade não comunga com a discriminação, com o desrespeito nem com a indiferença. As dificuldades enfrentadas por aqueles cujo o nome e o gênero postos no registro civil não são compatíveis com a sua identidade psíquica, já são, por si, o suficiente para justificar uma intervenção capaz de solucionar tal constrangimento. É próprio da dignidade a garantia da liberdade e da integralidade do indivíduo, permitindo que este seja quem, de fato, deseja ser, transbordando a sua subjetividade da forma que the convier.

\section{IDENTIDADE DE SEXO X IDENTIDADE PSÍQUICA - UMA ANÁLISE A PARTIR DA PERSPECTIVA DO DIREITO DE PERSONALIDADE}

Documentários, entrevistas e reportagens produzidas em várias partes do mundo trazem em seu conteúdo a difícil questão da transexualidade. Compreender acerca deste tema é algo que envolve muito mais que conceitos teóricos expressos em manuais. É um assunto delicado, munido de dores, sentimentos de inferioridade e não entendimento do que, de fato, ocorre com essas pessoas. Ter a oportunidade de assistir a essas histórias ou relacionar-se proximamente com um transexual pode ser uma experiência intensa e conflitante. Percebe-se que há uma forte dificuldade de aceitação. Primeiro deles consigo e depois da própria família, amigos e colegas. Não entender o que está acontecendo, ter raiva por ter nascido "no corpo errado" ou negar a si mesmo são fatos que frequentemente acontecem nesses casos.

O documentário americano "My Secret Self: A Story of Transgender Children", produzido pela American Broadcasting Company - $A B C$, traz a história de duas crianças e um adolescente que enfrentam o drama de serem transexuais. De acordo com a reportagem, muitas crianças transgêneras vivem nas sombras, se escondendo de um mundo que as vê como aberrações. Muitas vezes são rejeitadas pela própria família, pelos amigos e pela sociedade de uma maneira geral. Crescem odiando seu corpo biológico, o qual não passa de um verdadeiro calabouço, local onde não se identificam. Essa realidade é causa para diversas dores no corpo e na alma desses sujeitos, podendo, dentre outros resultados, adquirirem patologias como, por exemplo, a depressão, tornar-se usuários de drogas, sofrerem violências sociais em suas mais diversas searas, podendo chegar a praticar suicídio. Em uma das entrevistas feitas no citado programa, a mãe de Jazz, uma criança transexual de apenas seis 
anos que está em transição de menino para menina, compartilha alguns fatos ocorridos com o seu filho, o qual demonstra a falta de identidade com o gênero biológico desde muito criança.

Jazz's Mother: This baby came out, and basically said 'this is why I am a girl.'

Narrator: Jazz made it clear he wanted to wear a dress. Idoney 15 months he wouldn't snap is one seems we try to make it look like a dress.

Reporter: If you said to Jazz 'Good boy!', what the reaction be?

Jazz's Mother: Always, 'no mommy, good girl!' (20/20 Program, 2007)

Compreender tais questões é, sobretudo, reconhecer a juridicidade existencial de cada um. Todos são igualmente sujeitos de Direito equipados de garantias e prerrogativas irrenunciáveis. Entender que os transexuais são indivíduos que não comungam da forma física que thes é inerente e que o gênero do qual são oriundos não se assemelha ao gênero psíquico que de fato o constituem; abre portas para que se possa falar em Direitos essenciais. Esses direitos são, sobretudo, formadores da personalidade, sem os quais nada mais faria sentido. Cupis (1961, p. 17 - 18 apud ARAUJO, 2000, p. 10) afirma que:

(...) existem certos direitos sem os quais a personalidade restaria uma susceptibilidade completamente irrealizada, privado de todo o valor concreto: direitos sem os quais todos os outros direitos subjectivos perderiam todo o interesse para o indivíduo - o que equivale a dizer que, se eles não existissem, a pessoa não existiria como tal. São esses os chamados 'direitos essenciais', com os quais se identificam precisamente os direitos da personalidade. Que a denominação de direitos da personalidade seja reservada aos direitos es senciais justifica-se plenamente pela razão de que eles constituema medula da personalidade.

Assim, considera-se que o Direito de personalidade é um direito essencial, sendo a base da vida de todos os sujeitos. No entanto, a personalidade civil atribuída aos transexuais não é compatível com a realidade psíquica que lhes é inerente, afastando a sua identidade física da sua identidade psicológica. A incompatibilidade entre o registro civil e o sentimento interior de autoimagem dos transexuais é inteiramente turva, causando uma sensação de fragilidade e não acolhimento social. São cidadãos que carregam certidões que, na verdade, não são suas, limitando a sua real atuação enquanto indivíduos. Para os transexuais, revelar a sua identidade física é algo que traz sofrimento e os constrange, pois, em regra, há repulsa e desconforto com essa realidade. Como exemplo dessa realidade, pode-se citar parte da entrevista feito no documentário americano "My Secret Self: A Story of Transgender Children”, produzido pela American Broadcasting Company - ABC:

Reporter: Does will hire you fell sometimes that she's a fake?

Richard's Mother: Yes! She has in a physical deformity.

Reporter: She feels...

Richard's Mother: She has a birth defect with call it that.

(...)

Narrator: Then...an incidente in the bathtub convinced the Grants just how seriously confused their son was about his genderidentity. 


\begin{abstract}
Richard's Mother: Trial at the round one and when I came back on Richard was standing there very and somebody with and nail clipper and he was hot extend holding it on something that was closed. The yeah but it's a cringing but not exactly what I did. 'Buddy, what do you doing?' When he doing just looked at me with insights into 'mommy, doesn't do there...'

Reporter: He ir going cut it out? Cut te pênis out?

Richard's Mother: Yes. Gonna I did not know how does me no I'm yeah stack that took two-and-a-half and my mind I knew right there's something going on. (20/20 Program, 2007)
\end{abstract}

Esta dificuldade não poderia ser deixada de lado por nossa sociedade. O direito a ter a sua identidade psíquica reconhecida faz parte daquilo que se entende por moralmente justo e que deve ser acolhido. A personalidade incompatível nada mais é que fonte de acanhamento social, em nada facilitando para o desenvolvimento adequado do sujeito. Ferir o direito de personalidade é ferir a composição do indivíduo, o tornando algo que, na verdade, não o é. Conforme Diniz (2002, p. 135), o direito de personalidade.

São direitos subjetivos da pessoa de defender o que lhe é próprio, ou seja, a sua integridade física (vida, alimentos, próprio corpo vivo ou morto, corpo alheio, vivo ou morto, partes separadas do corpo vivo ou morto); a sua integridade intelectual (liberdade de pensamento, autoria científica, artística e literária) e sua integridade moral (honra, recato, segredo pessoal, profissional e doméstico, imagem, identidade pessoal, familiar e social).

Neste mesmo sentido e ainda acrescentando a palavra "psíquico", a qual é de extremo valor nesse caso, Gagliano e Pamplona Filho (2003, p. 144) colocam que direito de personalidade são "aqueles que têm por objetivo os atributos físicos, psíquicos e morais da pessoa em si e em suas projeções sociais". Diante destes conceito, entende-se que os transexuais portam uma personalidade mitigada, limitada ao estereótipo e rompendo com a complexa composição total de pessoa. O observável, em regra, não se faz, em si, capaz de classificar profundamente algo, diminuindo ainda mais essa possibilidade quanto o objeto em questão é uma máquina tão sublime e cheia de detalhes como, por exemplo, os seres humanos.

O direito de personalidade não deve, em hipótese nenhuma, ser fonte de obstáculo para a felicidade. A personalidade deve ter como objetivo a proteção da pessoa humana, atuando como manancial de cidadania e qualidade de vida. Não há como se falar em personalidade sem junto a ela apensar o desejo de uma realização pessoal no que tange aos seus aspectos físicos, psíquicos e morais. Só se pode falar em cidadania quando há, socialmente, o completo reconhecimento do sujeito, não the furtando nenhuma parte do quebra-cabeça que o personifica. De acordo com essa perspectiva, Tartuce (2014, p. 145), acrescenta que: 
Pelos conceitos transcritos, observa-se que os direitos da personalidade têmpor objeto os modos de ser, físicos ou morais do indivíduo e o que se busca proteger comeles são exatamente, os atributos específicos da personalidade, sendo personalidade a qualidade do ente considerado pessoa. Na sua especificação, a proteção envolve os as pectos psíquicos do indivíduo, além de sua integridade física, moral e intelectual, desde a sua concepção até a morte. Esse, na concepção deste autor, é o melhor conceito. (grifo original)

Diante do exposto, entende-se que não há como se falar de direito de personalidade e deste conceito retirar um de seus elementos essenciais, em especial o fator psíquico. A personalidade é do sujeito e, por isso, composta de subjetividade e individualidade. À sociedade não deveria caber a apreciação pronta e preconceituosa desta questão, sem que haja a observação detalhada de cada caso e de cada história. Assim, a mudança do prenome e do sexo posto no registro civil de uma pessoa que sofre de transtorno de identidade de gênero, mesmo que ainda na infância, pode ser o início de uma nova vida, desta vez, completa e digna.

\section{CONCLUSÃO}

Famílias de crianças que explicitamente não conseguem demonstrar afinidade com o seu sexo biológico, atravessam dificuldades sem respostas. Pais, responsáveis e professores não sabem ao certo que caminho seguir, tendo em vista que os projetos já criados pelo governo beneficiam apenas pacientes que já atingiram a maior idade. Desta forma, faz mister que estudos sejam desenvolvidos a fim de solucionar a problemática da transexualidade infantil e, assim, proporcionar uma vida digna neste período tão essencial para a formação humana como é a infância.

A partir da análise do princípio constitucional da dignidade humana, pode-se compreender que retirar dessas crianças o direito de ser, se comportar e vestir-se conforme the é inerente, pode ser considerado uma violência tão significativa quanto outras, fazendo com que este sujeito ainda tão imaturo sofra a dor de uma vida de privações. Desligar-se da dignidade é afastar-se de um dos maiores bens jurídicos garantidos na Constituição Federal de 1988, o qual se relaciona intimamente com o bem da vida e da liberdade.

O que se tem percebido é que os transexuais são seres que vivem nesta costa social. Sujeitos sem voz e sem vez, considerados portadores de uma patologia para a qual o tratamento que lhes é oferecido é a marginalização. Continuar nessa realidade é caminhar para um abismo, onde esses indivíduos nunca deveriam ser empurrados. É preciso entender que a transexualidade infantil não pode ser considerada uma fase, muito menos uma brincadeira 
como tantas outras próprias da idade. O transtorno de identidade de gênero precisa ser respeitado e trabalhado para que esses indivíduos possam crescer no seio de uma compreensão, a qual deve partir de si mesmo e do grupo.

A possibilidade de alterar o prenome e o gênero de crianças transexuais, mesmo que provisório, pode ser uma solução. Nesta pesquisa observa-se que as maiores queixas desses sujeitos é a impossibilidade de ser chamado pelo pronome compatível com sua identidade psíquica, não escolher as roupas conforme a sua preferência e não brincar de coisas com as quais tem afinidade. É certo que a genitália também é de um incomodo desmesurado para esses seres em formação, mas privar-se da vida social livre é algo próprio da indignidade, questão esta que o Direito não pode apartar-se.

Neste sentido, se faz primordial a análise de políticas públicas no sentido de diagnosticar e assistir, de maneira transdisciplinar, os transexuais desde o primeiro momento que esta questão for levantada. Têm-se que buscar soluções possíveis para sujeitos que sofrem com algo tão conflitante de forma tão prematura. Cogitar a possibilidade de alteração do prenome e gênero no registro civil ainda na infância, garantindo o bem-estar nos ambientes que a criança frequenta e a saúde prescrita pela OMS, pode ser um caminho para diminuir esta dor de ter nascido em um "corpo errado". Experiênciar os transtornos oriundos da falta de identidade com o próprio gênero biológico também é um assunto que deve ser abordado e dirimido pelo Estado, proporcionando aos transexuais a chave das primeiras portas de um longo caminho rumo ao alcance da dignidade.

É fato que, quando demonstrada ainda na infância, as intervenções cirúrgicas para solucionar a problemática aflorada pela transexualidade podem ser consideradas antecipadas e arrogantes, tendo em vista a sua irreversibilidade. É certo que a criança não possui capacidade para resolver suas questões de forma tão definitiva, como é o caso de uma cirurgia de mudança de sexo, mas, por outro lado, seria uma lapso do Estado fechar os olhos para a real possibilidade de sofrimentos psíquico decorrente de transtorno de identidade de gênero, mesmo que manifestado ainda no período pueril. 


\section{REFERÊNCIAS}

20/20 Program. My Secret Self: A Story of Transgender Children. Reporter: WALTERS, Barbara. Narrator: WALTERS, Barbara. Producer: GOLDBERG, Alan B. Editors:

SCHANZER, Joe; IWANO, Ruth. New York: American Broadcasting Company - ABC, 2007. Disponível em <https://www. youtube.com/watch?v=YU5NS4dHPUA>. Acesso em: 02 abril 2016.

ARÁN, Márcia; MURTA, Daniela. Do diagnóstico de transtorno de identidade de gênero às redescrições da experiência da transexualidade: uma reflexão sobre gênero, tecnologia e saúde. Physis - Revista de Saúde Coletiva, vol. 19, núm. 1, enero-marzo, 2009, pp. 15-41 Universidade do Estado do Rio de Janeiro Rio de Janeiro, Brasil Disponível em: < http://www.redalyc.org/pdf/4008/400838222003.pdf> Acesso em: 02 abril 2016.

ARAUJO, Luiz Alberto David. A proteção constitucional do transexual. São Paulo: Saraiva, 2000.

BENTO, Berenice; PELUCIO, Larissa. Despatologização do gênero: a politização das identidades abjetas. Rev. Estud. Fem., Florianópolis , v. 20, n. 2, p. 559-568, Aug. 2012. Disponível em: <http://www.scielo.br/scielo.php?script=sci_arttext\&pid=S0104026X2012000200017\&lng=en\&nrm=iso>. Acesso em: 02 abril 2016.

BEUREN, Ilse Maria. Trajetória da Construção de um Trabalho Monográfico em Contabilidade. In: BEUREN, Ilse Maria. (Org.). Como Elaborar Trabalhos Monográficos em Contabilidade: teoria e prática. 2. ed. São Paulo: Atlas, 2004.

BRASIL. Constituição (1988). Constituição da República Federativa do Brasil. Brasîlia, DF, Senado, 1988.

CANDIDO, Carla Laino. Freud: um monista mentalista?. Psic.: Teor. e Pesq., Brasilia , v. 19, n. 2, p. 127-133, 2003. Disponível em $<$ http://www.scielo.br/scielo.php? script=sci_arttext\&pid=S0102-

37722003000200004\&lng=en\&nrm=iso>. Acesso em: 02 abril 2016.

CERVO, Amado Luiz; BERVIAN, Pedro Alcino. Metodologia científica: para uso dos estudantes universitários. São Paulo: McGraw-Hill do Brasil, 1983.

COHEN, Cláudio. Os transtornos mentais e a justiça. Agencia iberoamericana para la difusión de la ciencia y la tecnologia. (DiCYT). Ciência Brasil. Salamanca - São Paulo: online, 2011. Disponível em: <http//www.dicyt.com/noticia/os-transtornos-mentais-e-ajustica> Acesso em: 02 abril 2016.

CUKIERT, Michele; PRISZKULNIK, Léia. Considerações sobre o eu e o corpo em Lacan. Estudos de Psicologia, v. 7, n. 1, p. 143-149, 2002. Disponível em: < https://scholar.google.com.br/scholar?ion=1\&espv=2\&bav=on.2,or.\&bvm=bv.118353311,d. Y 2I\&biw $=1366 \&$ bih $=574 \& d p r=1 \& u m=1 \&$ ie $=$ UTF-

8\&lr\&q=related:Eqra66EU5zyPaM:scholar.google.com/> Acesso em: 02 abril 2016.

DIAS, Maria Berenice. Um histórico da patologização da transexualidade e uma conclusão evidente: a diversidade é saudável. Revista Gênero \& Direito, n. 2, 2014. Disponível em: <http://periodicos.ufpb.br/ojs2/index.php/ged/article/viewFile/20049/11794>. Acesso em: 02 abril 2016. 
DINIZ, Maria Helena. As lacunas no direito. 7. Ed. São Paulo: Saraiva, 2002.

, Maria Helena. Dicionário Jurídico. V. 4 - Q-Z. São Paulo: Saraiva, 1998.

, Maria Helena. O Estado atual do biodireito. São Paulo: Saraiva, 2001.

DONIZETTI, Leila. Filiação Socioafetiva e Direito à Identidade Genética. Rio de Janeiro: Lumen Juris, 2007.

ELVIRA, Ascensión. El tratamiento jurídico de la transexualidad en Espanã desde un enfoque constitucional. In. Discriminação por Orientação Sexual - A homossexualidade e a transexualidade diante da experiência. Org. POMPEU, Gina Vidal Marcílio; SCAFF, Fernando Facury. Florianópolis: Conceito Editorial, 2012.

FAVARO, Vanessa Manchim. Prisma Científico: Transparência e dispersão de ideias. Blog WordPress. São Paulo: on-line, 2013. Disponível em

$<$ https://pris macientifico.wordpress.com/2013/08/23/meu-eu-secreto/\#more-2112>. Acesso em: 02 abril 2016.

G1. Jomal Nacional: Już autoriza mudança de gênero e nome para brasileira de 9 anos. Rio de Janeiro: G1, 2016. Disponível em: < http//g1.globo.com/jornal-nacional/noticia/2016/02/juiz-autoriza-mudanca-degenero-e-nome-para-brasileira-de-9-anos.html . Acesso em 22 de fevereiro de 2016.

GAGLiAnO, Pablo Stolze; PAMPLONA FILHO, Rodolfo. Novo Curso de Direito Civil. 4. ed. v. I. São Paulo: Saraiva, 2003.

GIL, Antônio Carlos. Métodos e técnicas de pesquisa social. 5. ed. São Paulo: Atlas, 1999.

KUMAGAI, Cibele; MARTA, Taís Nader. Princípio da dignidade da pessoa humana. In: Âmbito Jurídico, Rio Grande, XIII, n. 77, jun 2010. Disponível em: <http//www.ambitojuridico.com.br/site/index.php?n_link=revista_artigos_leitura\&artigo_id=7830>. Acesso em 22 fevereiro 2016.

LEMOS, Aline Maria Da Rocha. Novos posicionamentos do poder judiciário em face do estado democrático de direito. In. Acesso à justiça I [Recurso eletrônico on-line] organização CONPEDI/UFMG/ FUMEC/Dom Helder Câmara; coordenadores:Juvêncio Borges Silva, Tereza Cristina Sorice Baracho Thibau, Edinilson Donisete Machado Florianópolis: CONPEDI, 2015. Disponível em <http://www.conpedi.org.br/publicacoes/66fs1345/4qiqydiv/2POe1Fy1Vf3ha00a.pdf>. Acesso em 22 de fevereiro de 2016.

LÔBO, Paulo. Famílias. 2. ed. São Paulo: Saraiva, 2009.

MCCRUDDEN, Christopher. Human dignity and judicial interpretation of human rights. European Journal of international Law, v. 19, n. 4, p. 655-724, 2008. Disponível em: < http://ejil.oxfordjournals.org/content/19/4/655.full>. Acesso em 22 fevereiro de 2016.

MORAES, Maria Celina Bodin de. Danos à pessoa humana: uma leitura civil-constitucional dos danos morais. Rio de Janeiro: Renovar, 2003. 
NASIO, J. D. Cinco lições sobre a teoria de Jacques Lacan. Rio de Janeiro: Jorge Zahar, 1993.

OLIVEIRA, Carlindo Rodrigues de; OLIVEIRA, Regina Coeli de. Direitos sociais na constituição cidadã: um balanço de 21 anos. Serv. Soc. Soc., São Paulo , n. 105, p. 5-29, Mar. 2011 . Disponível em

$<$ http://www.scielo.br/scielo.php?script=sci_arttext\&pid=S0101-

66282011000100002\&lng=en\&nrm=iso>. Acesso em: 02 abril 2016.

OMS, Organização Mundial da Saúde. Constituição da Organização Mundial da Saúde (OMS/WHO) - 1946. USP. Disponível em:

$<$ http://www.direitoshumanos. usp.br/index.php/OMS-Organiza\%C3\%A7\%C3\%A3oMundial-da-Sa\%C3\%BAde/constituicao-da-organizacao-mundial-da-saude-oms who.html . Acesso em 22 fevereiro de 2016.

RAUPP, Fabiano Maury; BEUREN, Ilse Maria. Metodologia das Pesquisas Aplicável as Ciências Sociais. In: BEUREN, Ilse Maria. (Org.). Como Elaborar Trabalhos Monográficos em Contabilidade: teoria e prática. 2. ed. São Paulo: Atlas, 2004.

REALE, Miguel. Lições Preliminares de Direito. 27. ed. São Paulo: Saraiva, 2004.

RICHARDSON, Roberto Jarry. Pesquisa social: métodos e técnicas. 3. ed. São Paulo: Atlas, 1999.

SANTOS, Adriana Vieira et al. Justiça humanizada. 2006. Disponível em <http://egov.ufsc.br/portal/sites/default/files/anexos/15410-15411-1-PB.pdf >. Acesso em 22 de fevereiro de 2016.

SILVA, Aurélia Carla Queiroga da; BONIFÁCIO, Artur Cortez. Reflexos dos Direitos humanos nas relações jurídicas de Direito privado face às decisões do STF. In. Revista Direito e Liberdade - RDL - ESMARN - v. 14, n. 1, p. 99-121, jan./jun. 2012. Disponível em:

<http://www.esmarn.tjrn.jus.br/revistas/index.php/revista_direito_e_liberdade/article/viewFile /485/460>. Acesso em 22 fevereiro de 2016.

TARTUCE, Flávio. Direito Civil 1: Leis de Introdução e parte geral. 10 ed. rev., atual. e ampl. Rio de Janeiro: Forense; São Paulo: Método, 2014.

TEPEDINO, Gustavo. Cidadania e os direitos de personalidade. Revista da Escola Superior da Magistratura de Sergipe, Sergipe, n. 3, p. 23-44, 2002 